\title{
Finally accepting plant domestication
}

\author{
Agriculture has depended since its Neolithic origins upon spontaneous or induced genetic variation. Human \\ selection on naturally occurring variation in flowering is the most frequent source of domesticated crop plants. In the \\ current era of rapid technological advance in reading and writing genomes, we advocate universal access to some \\ safe modular variation in flower, leaf and color traits that can be operated without labs or restrictions by ordinary \\ farmers and gardeners.
}

$\mathrm{S}$ ebastian Soyk and colleagues (p 162) introduced mutations into a tomato that resulted in rapid synchronous flowering and a coordinated yield of early fruit. Variation in the gene target of this engineering is thought to have allowed tomato cultivation at latitudes far beyond its equatorial origins in South America. Also in this issue, Helmy Youssef and colleagues (pp 8 and 157) identify one of the flowering mutations that changes the ancestral two-row barley used in brewing into the protein-rich six-row barley used as animal fodder. The gene involved in this change controls not only the timing of phases of flower development but also the identities of the organs making up the grainbearing spike. Consequently, this mutation changes spike architecture and alters the plant's sugar production, influencing grain yield and nutritional composition. Genetic control of flowering time in rice is used to make specific hybrids as well as to regulate uniform harvests. It is also possible to deploy mutations altering flowering time to harvest crops before pathogens can become established or to alternate flowering time between early and late to disrupt pathogen prevalence and adaptation.

In offering consumers the products of a new technology, we should feed their economic opportunities as well as their bellies. To do this, we should seek to preserve their agency, offer a diversity of choice, and foster participation, understanding and community. We should listen and act on their feedback. While it is possible to invite a few of the public into labs to edit genes of plants that they can see growing for themselves, this, and the vast fields of optimized uniform grain, is unlikely to generate any enthusiasm for adoption of gene-edited foods in societies increasingly searching to exert control via organic, GMO-free and gluten-free labels. Instead, consumer genetic variation must come to the people, just as the informatics revolution put personal computers in every home rather than invite the public to submit punchcard programs at the mainframe.

The appropriate technology would be similar to that used by future seed corporations for tuning regulatory variation of key flowering, leaf morphology and color genes, and a range of levels of gene expres- sion could be achieved with arrays of transcription factor binding sites. Alternatively, genes could be modulated epigenetically via RNAdirected (or sequence-specific) control of DNA methylation or chromatin modification. Mutational variation in expression restricted to a specific gene or genes could be achieved by crossing the plant to a line that could destabilize or change the copy number of the regulatory element. Alternatively, gene expression might be tuned reversibly without mutation using an environmental condition or specific inducer of epigenetic modification. Such a period of adoption by participation is not unprecedented. For example, hybridization of all manner of flowers and crops in the early twentieth century led to an explosion of diversity, experiments and new discoveries by scientists and amateurs (like Luther Burbank) alike. Specially bred chrysanthemums together with very specific application of heat and light produce spectacular floral firework displays in the hands of Japanese horticultural experts.

The benefits of putting a set of variation and selection lines back into the hands of farmers and the gardening public would go beyond creating a social license to operate for gene technologies. There are many questions about local growth conditions and consumer preference that could be crowdsourced for participatory feedback. Other benefits might accrue in advertising by word of mouth and social media. Niche farm markets would bloom. The creators of the technology would vie to buy back improved versions of their creations under licensing that would encourage fine-tuning and innovation to solve specific problems deemed not economic to solve in detail in house.

Giving up social control of gene control technology to generate public acceptance is not as counterintuitive as it seems at first sight. We have been mutating, crossing and selecting plants for tens of thousands of years. To reject gene-edited food as unnatural is as nonsensical as denying agriculture. It is time to reconcile ourselves to our roles in humanplant coevolution and redomesticate plant domestication in our own homes. 